\title{
Disparities in cystic fibrosis survival in Mexico: Impact of socioeconomical status
}

\author{
Adriana Bustamante ${ }^{1}$, Lucia Fernandez ${ }^{1}$, Lissette Rivas ${ }^{1}$, and Roberto Mercado Longoria ${ }^{1}$ \\ ${ }^{1}$ Hospital Universitario Dr Jose Eleuterio Gonzalez
}

November 17, 2020

\begin{abstract}
Background. Median survival age in cystic fibrosis (CF) has increased in developed countries. Scarce literature exists about survival in Latin American, especially in Mexico. The aim of our study was to assess the median age of CF patients' survival in Mexico over a 20-year period. Methods. We conducted a retrospective study, with all patients registered and followed in the $\mathrm{CF}$ Center in Monterrey, Mexico from 2000 to 2020. Median survival age was the primary outcome, assessed with the Kaplan-Meier analysis. Influence of clinical, biological, and demographic factors on survival were analyzed with the Cox regression model. Results. Two-hundred five patients were included. Median survival for the cohort was 21.37 years (95\% CI $17.20-25.55)$. In the multivariate Cox regression model, low socioeconomic status (hazard ratio [HR] 4.21, 95\% CI 2.43 - 7.27), chronic Pseudomonas aeruginosa (P. aeruginosa) infection at 6 years (HR 10.45, 95\% CI 5.66 - 19.28), and pancreatic insufficiency (HR $3.13,1.38$ - 7.13) were independent risk factors for mortality. Conclusion. Median survival in Mexican patients with $\mathrm{CF}$ is lower than in high-income countries, and socioeconomic status plays a conspicuous role in the disparity. To increase patient survival for those residing in low-income countries, public health authorities must design policies that fully cover diagnosis and treatment strategies for the CF population.
\end{abstract}

\section{INTRODUCTION}

Cystic fibrosis $(\mathrm{CF})$ is a hereditary disease, transmitted in an autosomal recessive manner; its prevalence varies by country, according to ethnic composition. In Mexico, its prevalence is estimated to be approximately 1: 8,500 to $1: 10,000$ in live newborns. ${ }^{1}$

Survival of those with CF has improved markedly in developed countries, due to early diagnosis, multidisciplinary care, aggressive nutritional supplementation, novel inhaled treatments, eradication of Pseudomonas aeruginosa $\left(P\right.$. aeruginosa), and lung transplantation. ${ }^{2}$

Despite advances, there is a great deal of variability in disease progression, severity, and survival in different countries and geographic settings., ${ }^{3,4}$ There are several factors related to survival, such as the cystic fibrosis transmembrane conductance regulator (CFTR) genotype, ${ }^{5}$ initial presentation of the disease, ${ }^{6}$ nutritional status,${ }^{7}$ sputum bacteriology,${ }^{8,9}$ diabetes,${ }^{10-12}$ socioeconomic status (SES) ${ }^{13}$ pulmonary exacerbations, ${ }^{14}$ gender, ${ }^{15}$ and follow-up in a specialized center. ${ }^{15}$

In England and Wales, children with CF from lower socioeconomic groups were nearly three times more likely to die at an early age than those of higher economic status. ${ }^{13}$ In Latin America, particularly Mexico, limited information exists on the survival of CF patients, including factors that impact survival. To address this, the aim of our study is to assess the median age of CF patient survival in northeast Mexico over a 20-year period.

\section{MATERIALS AND METHODS}


We conducted a retrospective study, including all patients with $\mathrm{CF}$ who were registered and followed between April 2000 and April 2020 in the CF Center at University Hospital (Dr. José E. González in Monterrey Mexico). Demographic, clinical, and biological variables were documented, such as gender sex, age at diagnosis, SES, pancreatic status, CFTR genotypes, and diagnosis of chronic infection with P. aeruginosa at 6 years. Age at diagnosis was categorized as [?] 2 years, $3-18$ years, $>18$ years. SES was evaluated using the Asociacion Mexicana de Agencias de Inteligencia de Mercado y Opinion (AMAI) score, with patients divided in high $(\mathrm{AB}, \mathrm{C}+$, and $\mathrm{C})$ and low socioeconomic levels $(\mathrm{C}, \mathrm{D} \text {, and } \mathrm{E})^{16}$. A pancreatic-insufficient or pancreatic-sufficient classification was based on enzyme usage. ${ }^{2}$ Genotype was classified as homozygous for F508 $\Delta$ mutation, heterozygous for F508 $\Delta$ mutation, and other or missing. Quarterly sputum or oropharyngeal swab bacteriology in the first 6 years were evaluated to detect chronic infection with $P$. aeruginosa, using Leeds Criteria. ${ }^{17}$

The Mexican health system is complex; it is comprised of two sectors: public and private. The public sector includes: (1) Social security institutions [Instituto Mexicano del Seguro Social (IMSS), Instituto de Seguridad y Servicios Sociales de los Trabajadores del Estado (ISSSTE), Petróleos Mexicanos (PEMEX), Ministry of Defense (SEDENA), Ministry of the Navy (SEMAR), and (2) programs that cover the population without social security [Ministry of Health (SSa), State Health Services (SESA), IMSS-Oportunidades (IMSSO), Seguro Popular (SPS)]. The private sector is comprised of insurance companies and service providers, working in both private clinics and hospitals. ${ }^{18}$ Access to tobramycin varies according to health coverage; currently, patients belonging to ISSSTE, PEMEX, SEDENA SEMAR, SPS, and the majority of patients from private health insurance companies have access to this drug.

This study was approved by the Institutional Research Ethics Committee.

Statistical analysis

SPSS v. 22 (IBM SPSS Statistics, IBM Corporation, Chicago, IL, USA) was used for data analysis. Descriptive analysis for continuous variables was performed. Categorical variables were displayed as absolute numbers and percentages. Median survival age was the primary outcome, ${ }^{19}$ assessed by the Kaplan-Meier analysis; groups were compared with the log-rank test. Duration of survival was defined as the time between the date of birth and date of death, or the last follow-up. Median age at death was calculated for all individuals in the cohort. Influence of risk factors was assessed by a uni- and multivariate Cox regression model, with $95 \%$ confidence intervals $(\mathrm{CI})$. A $\mathrm{P}$ value $<0.05$ was considered significant.

\section{RESULTS}

A total of 210 individuals with CF were followed in the CF Center from 2000 to 2020; five patients were excluded due to missing data and 205 patients were included in the study cohort. Ninety-nine patients were female (48.3\%). Mutation analysis was available for 156 patients $(76.1 \%)$. Patient characteristics are described in Table 1. Median age at diagnosis was 1 year (1 month - 34 years). Median survival age for the cohort was 21.37 years (95\% CI 17.20 - 25.55). Median survival age for high SES was 29.46 years (95\% CI $24.09-34.83)$ vs 15.12 years $(95 \%$ CI $11.78-18.45)$ for low SES $(\mathrm{p}<0.001)$. Patients with a diagnosis of chronic infection of P. aeruginosa at 6 years had a median survival of 12.41 years (95\% CI 10.11 - 14.73) compared to 35.25 years $(95 \%$ CI 26.61 - 43.70) for patients with no evidence of chronic infection at 6 years $(\mathrm{p}=0.030)$. Differences in median survival age are presented in Table 2. Survival curves by SES and by $P$. aeruginosa chronic infection status are displayed in Figure 1. Differences in survival were statistically significant $(\mathrm{p}<0.001, \mathrm{p}<0.001)$.

Median age at death for the cohort was 12.46 years ( 1 month -43.65 years). Median age at death in the first 5 -year period $(2000-2005)$ was 9.55 years $(1$ month - 30.61 years $)$, while for the last 5 -year period (2016 - 2020), it was 15.49 years ( 5 months -39.27 years) $(\mathrm{p}=0.012)$. Median age at death according to gender, SES, presence of chronic $P$. aeruginosa infection at 6 years, pancreatic status, and genotype are shown in Table 3.

Uni- and multivariable Cox regression analyses for mortality are shown in Table 4. Variables that reached 
significance in the multivariate model were chronic $P$. aeruginosainfection at 6 years, low SES, and pancreatic insufficiency.

\section{DISCUSSION}

Disparities in CF survival are the result of a deeply complex interaction between many factors, with SES playing a conspicuous role. Worldwide, median survival in patients with CF varies from country to country; it is estimated between 40 - 50 years, with a lower median survival and worse prognosis in female patients. ${ }^{2,} 15,20$ With current treatment strategies, most patients will be able to reach adulthood; however, it remains a life-shortening disease. In addition, new therapies with CFTR modulators and inhaled antibiotics are not widely available in low-middle income countries, such as Mexico, issues that decidedly limit survival in CF patients.

Among factors that influence survival, socioeconomic status plays a major role in $\mathrm{CF}$ as in many other chronic diseases. ${ }^{13,} 21,22$ The low SES is related to food insecurity, air pollution, reduced access to prompt diagnosis, and specialized treatments due to their high cost and a lack of healthcare coverage. ${ }^{23}$ Patients with low SES and CF have higher mortality, ${ }^{24}$ worse lung function, ${ }^{25}$ lower body mass index, more pulmonary exacerbations, ${ }^{26}$ and higher risk of $P$. aeruginosa infection. ${ }^{27}$

In addition, chronic infection with $P$. aeruginosa is a factor closely linked to the SES in Mexico, as many lowincome children do not have access to inhaled antibiotics. The only inhaled antibiotic available (tobramycin) costs around $\$ 2000$ dollars per month and is not supplied by social security institutions that provide care for more than half the patients. As previously reported by our group, Mexican CF patients tend to have their first infection with $P$. aeruginosaearly in life, ${ }^{28}$ while a significant percentage $(37 \%)$ present chronic infection with this bacterium at 6 years of age.

In the present study, patients with low SES were four times more likely to have shortened survival, compared to their high SES counterparts; median survival for the low SES group was half that observed in the highincome group. Chronic infection with $P$. aeruginosa and pancreatic insufficiency, along with low SES, were independent predictors of mortality.

Regarding CFTR genotypes and their connection to median survival, no significant difference was observed in the study population. Yet, patients with pancreatic insufficiency, a marker for severe mutations, had significantly lower survival rates than those with sufficiency.

In relation to the CFTR genotype, the risk of meconium ileus (MI) varies between $12.5 \%$ to $24.9 \%$, as reported by the United States Patient Registry. ${ }^{29}$ In our cohort, the frequency of MI was $7.8 \%$. A similar frequency $(7.3 \%)$ was reported by another group in Mexico. ${ }^{30}$ This low prevalence rate may be attributed to high heterogeneity in CFTR mutations found in the Mexican population. ${ }^{31}$

In our study, CF-related diabetes was present in $7.3 \%$ of patients, while in the literature the incidence varies according to age, from $2.5 \%$ in children and reaching $40-50 \%$ in adults. ${ }^{10,12}$ This relatively low frequency may be due to the cohort being comprised of a young population, as the number of patients who reached adulthood remained low.

As previously mentioned, gender is an additional factor that impacts survival. The cause of this gender gap in CF remains unclear, but some studies suggest that it may be related to reduced activity levels, poor nutritional status, and the effect of estrogens in female patients. ${ }^{32-34}$ In this cohort, male patients had greater survival, but this difference was statistically insignificant.

In our population, median survival was 21.4 years, with these values below the median reported in highincome countries; for example, Canada has a median survival of 49.7 years. $^{2}$ These data must be interpreted, while looking at several limitations: the study was conducted in a single center in North Mexico, its retrospective nature, and mutation analysis was not available to all patients. Despite these limitations, our study provides valuable information as its design, based on longitudinal follow-up by the same specialized team, 
minimized results bias as a consequence of heterogeneity in therapeutic interventions. Moreover, there is scarce information on survival in patients residing in Latin America, especially in Mexico.

In conclusion, socioeconomic status plays a decisive role in CF patient survival, together with P. aeruginosa chronic infection, independent risk factors which are closely linked. To increase patient survival in low-income countries, public health authorities must design policies that fully cover diagnosis and treatment strategies in the $\mathrm{CF}$ population.

\section{Acknowledgments: None}

Conflict of Interest: The authors have no conflict of interest to declare.

\section{Reference}

1. Organization WH. The molecular genetic epidemiology of Cystic Fibrosis : report of a joint meeting of WHO/ECFTN/ICF(M)A/ECFS. Genoa, Italy - 19 june 20022004.

2. Stephenson AL, Tom M, Berthiaume Y, Singer LG, Aaron SD, Whitmore GA, et al. A contemporary survival analysis of individuals with cystic fibrosis: a cohort study. Eur Respir J. 2015;45(3):670-9.

3. Mehta G, Macek M, Mehta A, Group ERW. Cystic fibrosis across Europe: EuroCareCF analysis of demographic data from 35 countries. J Cyst Fibros. 2010;9 Suppl 2:S5-S21.

4. Salvatore D, Buzzetti R, Mastella G. Update of literature from cystic fibrosis registries 2012-2015. Part 6: Epidemiology, nutrition and complications. Pediatr Pulmonol. 2017;52(3):390-8.

5. MacKenzie T, Gifford AH, Sabadosa KA, Quinton HB, Knapp EA, Goss CH, et al. Longevity of patients with cystic fibrosis in 2000 to 2010 and beyond: survival analysis of the Cystic Fibrosis Foundation patient registry. Ann Intern Med. 2014;161(4):233-41.

6. Lai HJ, Cheng Y, Cho H, Kosorok MR, Farrell PM. Association between initial disease presentation, lung disease outcomes, and survival in patients with cystic fibrosis. Am J Epidemiol. 2004;159(6):537-46.

7. Yen EH, Quinton H, Borowitz D. Better nutritional status in early childhood is associated with improved clinical outcomes and survival in patients with cystic fibrosis. J Pediatr. 2013;162(3):530-5.e1.

8. Emerson J, Rosenfeld M, McNamara S, Ramsey B, Gibson RL. Pseudomonas aeruginosa and other predictors of mortality and morbidity in young children with cystic fibrosis. Pediatr Pulmonol. 2002;34(2):91100.

9. Blanchard AC, Waters VJ. Microbiology of Cystic Fibrosis Airway Disease. Semin Respir Crit Care Med. 2019;40(6):727-36.

10. O’Shea D, O'Connell J. Cystic fibrosis related diabetes. Curr Diab Rep. 2014;14(8):511.

11. Chamnan P, Shine BS, Haworth CS, Bilton D, Adler AI. Diabetes as a determinant of mortality in cystic fibrosis. Diabetes Care. 2010;33(2):311-6.

12. Moran A, Dunitz J, Nathan B, Saeed A, Holme B, Thomas W. Cystic fibrosis-related diabetes: current trends in prevalence, incidence, and mortality. Diabetes Care. 2009;32(9):1626-31.

13. Barr HL, Britton J, Smyth AR, Fogarty AW. Association between socioeconomic status, sex, and age at death from cystic fibrosis in England and Wales (1959 to 2008): cross sectional study. BMJ. 2011;343:d4662.

14. Waters V, Ratjen F. Pulmonary Exacerbations in Children with Cystic Fibrosis. Ann Am Thorac Soc. 2015;12 Suppl 2:S200-6.

15. Harness-Brumley CL, Elliott AC, Rosenbluth DB, Raghavan D, Jain R. Gender differences in outcomes of patients with cystic fibrosis. J Womens Health (Larchmt). 2014;23(12):1012-20.

16. H. L-R. Los niveles socioeconomicos en Mexico y la distribucion del gasto. 2009. 
17. Lee TW, Brownlee KG, Conway SP, Denton M, Littlewood JM. Evaluation of a new definition for chronic Pseudomonas aeruginosa infection in cystic fibrosis patients. J Cyst Fibros. 2003;2(1):29-34.

18. Gomez Dantes O, Sesma S, Becerril VM, Knaul FM, Arreola H, Frenk J. [The health system of Mexico]. Salud Publica Mex. 2011;53 Suppl 2:s220-32.

19. Keogh RH, Stanojevic S. A guide to interpreting estimated median age of survival in cystic fibrosis patient registry reports. J Cyst Fibros. 2018;17(2):213-7.

20. Foundation CF. 2019 Cystic fibrosis Foundation Patient Registry Highlights. 2019.

21. Kerem E, Cohen-Cymberknoh M. Disparities in Cystic Fibrosis Care and Outcome: Socioeconomic Status and Beyond. Chest. 2016;149(2):298-300.

22. Schechter MS, Shelton BJ, Margolis PA, Fitzsimmons SC. The association of socioeconomic status with outcomes in cystic fibrosis patients in the United States. Am J Respir Crit Care Med. 2001;163(6):1331-7.

23. Schechter MS, McColley SA, Silva S, Haselkorn T, Konstan MW, Wagener JS, et al. Association of socioeconomic status with the use of chronic therapies and healthcare utilization in children with cystic fibrosis. J Pediatr. 2009;155(5):634-9.e1-4.

24. O'Connor GT, Quinton HB, Kneeland T, Kahn R, Lever T, Maddock J, et al. Median household income and mortality rate in cystic fibrosis. Pediatrics. 2003;111(4 Pt 1):e333-9.

25. Taylor-Robinson DC, Thielen K, Pressler T, Olesen HV, Diderichsen F, Diggle PJ, et al. Low socioeconomic status is associated with worse lung function in the Danish cystic fibrosis population. Eur Respir J. 2014;44(5):1363-6.

26. Watts KD, Seshadri R, Sullivan C, McColley SA. Increased prevalence of risk factors for morbidity and mortality in the US Hispanic CF population. Pediatr Pulmonol. 2009;44(6):594-601.

27. McGarry ME, Williams WA, McColley SA. The demographics of adverse outcomes in cystic fibrosis. Pediatr Pulmonol. 2019;54 Suppl 3:S74-S83.

28. E BA. Early acquisition of Pseudomonas aeruginosa in Mexican children with cystic fibrosis. Acta Pediatr Mex; 2020. p. 159-64.

29. Sathe M, Houwen R. Meconium ileus in Cystic Fibrosis. J Cyst Fibros. 2017;16 Suppl 2:S32-S9.

30. E Y. Correlacion genotipo -fenotipo en una muestra de pacientes mexicanos con fibrosis quistica. Rev Invest Clin; 2013. p. 491-9.

31. Chavez-Saldana M, Yokoyama E, Lezana JL, Carnevale A, Macias M, Vigueras RM, et al. CFTR allelic heterogeneity in Mexican patients with cystic fibrosis: implications for molecular screening. Rev Invest Clin. 2010;62(6):546-52.

32. Selvadurai HC, Blimkie CJ, Cooper PJ, Mellis CM, Van Asperen PP. Gender differences in habitual activity in children with cystic fibrosis. Arch Dis Child. 2004;89(10):928-33.

33. Zeitlin PL. Cystic fibrosis and estrogens: a perfect storm. J Clin Invest. 2008;118(12):3841-4.

34. Fogarty AW, Britton J, Clayton A, Smyth AR. Are measures of body habitus associated with mortality in cystic fibrosis? Chest. 2012;142(3):712-7.

\section{Hosted file}

Tablas articulo sobrevida mexico fq version4.pdf available at https://authorea.com/users/ 376413/articles/493367-disparities-in-cystic-fibrosis-survival-in-mexico-impact-ofsocioeconomical-status 

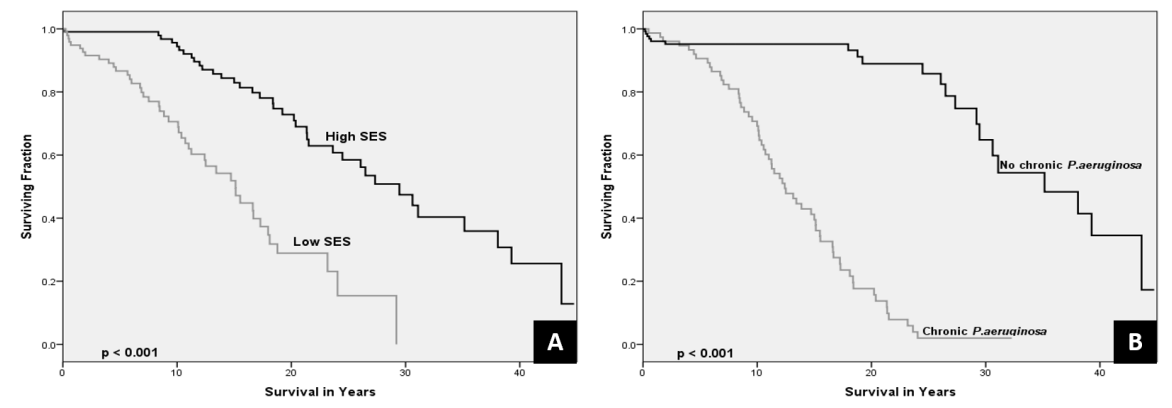